\title{
Application of compound mixture of caprylic acid, iron and mannan oligosaccharide against Sparicotyle chrysophrii (Monogenea: Polyopisthocotylea) in gilthead sea bream, Sparus aurata
}

\author{
George Rigos $^{1}$, Ivona Mladineo ${ }^{2}$, Chrysa Nikoloudaki $^{1}$, Anamarija Vrbatovic ${ }^{2}$ and Dimitra Kogiannou $^{1}$ \\ ${ }^{1}$ Institute of Marine Biology, Biotechnology \& Aquaculture, Hellenic Center for Marine Research, Aghios Kosmas, Hellinikon, \\ Athens, Greece; \\ ${ }^{2}$ Institute of Oceanography and Fisheries, Split, Croatia
}

\begin{abstract}
We have evaluated the therapeutic effect of a compound mixture of caprylic acid ( $200 \mathrm{mg} / \mathrm{kg}$ fish), organic iron ( $0.2 \%$ of diet) and mannan oligosaccharide ( $0.4 \%$ of diet) in gilthead sea bream, Sparus aurata Linnaeus, infected with Sparicotyle chrysophrii Beneden et Hesse, 1863 in controlled conditions. One hundred and ten reared and S. chrysophrii-free fish (197 g) located in a cement tank were infected by the parasite two weeks following the addition of $150 \mathrm{~S}$. chrysophrii-infected fish $(70 \mathrm{~g})$. Growth parameters and gill parasitic load were measured in treated against control fish after a ten-week-period. Differences in final weight, feed conversion ratio, specific growth rate and feed efficiency were not statistically significant between the experimental groups, suggesting no evident effect with respect to fish growth during the study period. Although the prevalence of S. chrysophrii was not affected by the mixture at the end of the experiment, the number of adults and larvae was significantly lower. The mean intensity encompassing the number of adults and larvae was 8.1 in treated $v s 17.7$ in control fish. Individual comparisons of gill arches showed that the preferred parasitism site for $S$. chrysophrii it the outermost or fourth gill arch, consistently apparent in fish fed the modified diet and in control fish. In conclusion, the combined application of caprylic acid, organic iron and mannan oligosaccharide can significantly affect the evolution of infection with $S$. chrysophrii in gilthead sea bream, being capable of reducing adult and larval stages of the monogenean. However, no difference in growth improvement was observed after the trial period, potentially leaving space for further optimisation of the added dietary compounds.
\end{abstract}

Keywords: Monogeneans, MOS, treatment, Sparidae

This article contains supporting information (Tables S1, S2) online at http://folia.paru.cas.cz/supp1/2016-63-027.pdf

Monogeneans are ubiquitous and abundant in the aquatic environment. Being mostly isolated from fish, it is estimated that $95 \%$ of species parasitise as ectoparasites on the gills and skin (Euzet and Combes 1998). The aquaculture environment, in particular, which is characterised by high fish density, close vicinity of different age categories of reared fish, as well as wild populations, high load of organic matter resulting from feed and fecal particles,is known as an 'amplifier' of parasites, among which monogeneans play a prominent role (Nowak 2007).

So far, the only reported polyopisthocotylean monogenean Sparicotyle chrysophrii Van Beneden et Hesse, 1863 significantly affecting the financial sustainability of Mediterranean farms has been isolated from the gilthead sea bream, Sparus aurata Linnaeus, and represents the only species within genus Sparicotyle Mamaev, 1984. It has been recorded in marine cages in the Adriatic, Aegean, Egyptian coast, Eilat, Gulf of Lion, Ionian, Israeli coast, Ligurian Sea,
Northeast Atlantic and Tyrrhenian (Faisal and Iman 1990, Radujković and Šundić 2014). It causes mortality when contracted at high prevalence (Sanz 1992, Alvarez-Pellitero 2004, Vagianou et al. 2006), growth retardation (Antonelli et al. 2010), while pronounced pathology is observed even at low infection intensity (eight parasites per gill arch) (Mahmoud et al. 2014). The infection in reared gilthead sea bream, apart from gross pathology of gills due to necrosis, causes lethargy due to hypoxia and severe anaemia (Sitjà-Bobadilla et al. 2006), while histopatology encompasses lamellar shortening, clubbing and synechiae, proliferation of the epithelial tissue with resulting fusion of the secondary lamellae, and marked presence of chloride cells (Sitjà-Bobadilla and Alvarez-Pellitero 2009). More importantly, the total feed conversion rate (FCR) of gilthead sea bream has recently increased by a factor of $>0.4$ due to infections with S. chrysophrii, increasing the feed requirement for $>50000$ tons in Mediterranean production (G.R. - unpubl. data).

Address for correspondence: G. Rigos, Institute of Marine Biology, Biotechnology \& Aquaculture, Hellenic Center for Marine Research, Aghios Kosmas, 16777 Hellinikon, Athens, Greece. Phone: +302109856721; Fax: +302109829239; E-mail: grigos@hcmr.gr 
De Vico et al. (2008) observed a dramatic increase in size and numbers of splenic melanomacrophage centres in the spleen of infected gilthead sea breams, suggesting an increase in hemosiderin and lipofuscin, hallmarks of erythrocyte destruction, tissue catabolism and degenerative chronic disorder (Agius and Roberts 1981, Agius and Agbede 1984). In addition, secondary infections with other parasites and bacteria are common for the S. chrysophrii-infected gilthead sea bream (Cruz et al. 1997).

In order to apply treatments in a more environmentally-sustainable way and decrease intensive labour requirements for bath treatment in sea cages, Rigos et al. (2013) have developed a modified diet containing caprylic acid (CA), an eight-carbon saturated fatty acid that is effective against ectoparasites, which is practical to amply and safe for the host, consumers and the environment. Although its antiparasitic mechanisms are not fully understood, it seems that its lipotrophic properties enable dissolution of the pathogen cell membrane and consequent disequilibrium in fluidity and permeability, leading to membrane disaggregation or malfunction (Kato and Shibasaki 1976, Bergsson et al. 1998, Sun et al. 2003). In case of early infection with S. chrysophrii, a dietary dosing of $200 \mathrm{mgCA} / \mathrm{kg}$ for 60 days can significantly reduce parasite intensity when low infestation is established, but the compound has no effect on overall growth rate as expected (Rigos et al. 2013).

Therefore, based on previous experience, the aim of the present study the aim was to optimise the experimental supplementation of CA by the addition of an organic iron and mannan oligosaccharide (MOS) and assess the effect of the new mixture on parasite parameters (prevalence, mean abundance and intensity) and growth in fish fed a modified diet and control gilthead sea bream over two months. Iron would possibly attenuate the detrimental effect of anaemia suffered by sea bream due to infection with $S$. chrysophrii (Sitjà-Bobadilla et al. 2006), as has been empirically observed in Greece.

MOS has proven to be effective in enhancing growth and the immune functions of European sea bass (Torrecillas et al. 2007) and was added in the mixture, as the cellular and innate immune responses of $S$. chrysophrii-infected gilthead sea bream are affected (Henry et al. 2015). The beneficial effects of dietary iron supplementation on gilthead sea bream have been previously investigated, as reflected by a significant increase in the number of red blood cells ( $\mathrm{Ri}$ gos et al. 2010). The chosen dosages of mixture compounds in the modified diet were based on an earlier kinetic study performed in controlled conditions and pertinent literature (Rigos et al. 2010, 2013, Sweetman et al. 2010).

\section{MATERIALS AND METHODS}

The model applierd for experimental treatment of infected gilthead sea bream with a diet supplemented with a mixture of caprylic acid, iron and MOS (CIM) was based on a recent study by Rigos et al. (2015). Briefly, 110 healthy and parasite-free fish (197 $\pm 22 \mathrm{~g}$ ), previously maintained in land tanks, were equally distributed in six net cages $\left(1 \mathrm{~m}^{3}\right)$ located in an inland cement tank $\left(50 \mathrm{~m}^{3}\right)$ at the facilities of the Hellenic Centre for Marine Research - HCMR (Athens, Greece). Three cages served as the control and the remaining for the treated group. Two weeks after the introduction of recipient fish and administration of the CIM diet, 150 gilthead sea bream $(70 \pm 13 \mathrm{~g})$ naturally infected with Sparicotyle chrysophrii, were transferred to the facilities. Donor fish originated from a farming site in south Evoikos Gulf, central Greece. In situ parasitological examination of 20 fish revealed a $100 \%$ prevalence and $15 \pm 3$ parasitic intensity (adults plus larvae), measured in the two external gill arches. After transfer, donor fish were introduced into the cement tank harbouring the healthy caged fish and were left to swim outside the cage net containing the recipient fish. Likewise, donor fish did not interfere with the feeding environment of the recipient fish and remained unfed until the termination of the trial. Fish tanks were continuously supplied with aerated flow-through sea water. The water flow in the challenge tank was equally maintained throughout the experiment and based on eight different inflow points located on both sides of the tank. This set up was created to maximise uniformity in the distribution of the infection by the free-swimming infection stages. The experiment lasted 10 weeks and water temperature ranged from $22^{\circ} \mathrm{C}$ in autumn to $27^{\circ} \mathrm{C}$ in summer.

Two experimental extruded diets (Clextral extruder, Firminy, France) were prepared at the facilities of HCMR (Table 1). One diet was used as control and the second one, described as modified, was supplemented by $1 \%$ CA (Biomar, Volos, Magnesia, Greece), $0.2 \%$ organic iron (Bioplex, Alltech, Lexington, Kentucky, USA) and $0.4 \%$ MOS (Bio-Moss, Alltech, Lexington, Kentucky, USA). All fish were hand-fed once (2 PM) at a daily rate of $2 \%$ body weight (BW) (representing a dosing of $200 \mathrm{mg} \mathrm{CA} / \mathrm{kg}$ fish in treated fish). Feed consumption was recorded daily. At the end of the experiment, all surviving experimental fish were weighted individually and the following growth parameters were calculated:

Feed Conversion Rate = daily FI (g)/ wet weight gain (g).

Specific Growth Rate $(\mathrm{SGR})=100 \times\left[\ln \left(\mathrm{W}_{1}\right)-\ln \left(\mathrm{W}_{0}\right)\right] /$ rearing days.

Feed Efficiency $(\mathrm{FE})=\left(\mathrm{W}_{1}-\mathrm{W}_{0}\right) \times 100 /$ dry feed intake

In the aforementioned formulae, $\mathrm{FI}$ is feed intake, $\mathrm{W}_{0}$ and $\mathrm{W}_{1}$ are the initial and the final mean weight of fish in grams.

Prior to transfer of the recipient fish to the experimental cages of inland tanks, external gills from randomly chosen fish of the maintained stock were subjected to the stereoscopical analysis in order to ascertain the absence of the parasite. Two weeks after the introduction of donor fish, 12 recipient fish randomly selected from the 6 cages were examined for the presence of the parasite, as above. At the end of the experiment, all surviving experimental fish were killed by blow to the head and all gill arches were subjected to stereoscopical examination in order to count adult monogeneans and larvae per gill, divided into left (L1, L2, L3, L4) and right (R1, R2, R3, R4) gill arches. An SZ61 Olympus stereoscope at $\times 0.67$ magnification (Olympus, PA, USA) equipped with a digital camera (Infinity Lite, Lumenera, Ottawa, Ontario, Canada) was used. The growth parameters of treated vs control fish were evaluated using Student's t-test (Statistical software SPSS 18.0) with 95\% confidence level.

Quantitative Parasitology 3.0 software (Rózsa et al. 2000, Reiczigel and Rózsa 2005) was used to analyse the parameters of infection with S. chrysophrii in control (C) and treated (T) fish, deploying prevalence, mean abundance and intensity of infection according to Bush et al. (1997). Prevalence values were supported by Sterne's exact $95 \%$ confidence interval (CI) and mean abundance and intensity by bootstrap $95 \% \mathrm{CI}(\mathrm{N}=2000)$. The negative 
Table 1. Composition of control and modified diets used in experimental treatment of infection with Sparicotyle chrysophrii in gilthead sea bream, Sparus aurata.

\begin{tabular}{lcc}
\hline & Control diet & Modified diet \\
\hline Raw material & \multicolumn{2}{c}{ Weight (g/1 kg) } \\
\hline Maize gluten 60 (min. 58\%) & 249.6 & 249.6 \\
Fish meal NA STD 70\% & 200.0 & 200.0 \\
Soya HP48, Non GMO & 200.0 & 200.0 \\
Fish oil, trimmings & 120.0 & 110.0 \\
Wheat & 114.0 & 114.0 \\
Wheat gluten, min. 80\% & 49.0 & 49.0 \\
Water change & 25.0 & 25.0 \\
Fish oil, 18 EPA+DHA & 20.0 & 20.0 \\
Mono-calcium phosphate (MCP) & 12.4 & 12.4 \\
L-Lysine HCI (78\%) & 5.0 & 5.0 \\
Premix & 5.0 & 5.0 \\
Caprylic acid (200 mg/ kg fish) & 0 & 10.0 \\
Organic iron & 0 & 2.0 \\
Mannan oligosaccharide & 0 & 4.0 \\
\hline Nutrient & \multicolumn{2}{c}{ Value (\%) } \\
\hline Protein & 43.5 & 43.5 \\
Fat & 17.8 & 17.8 \\
Ash & 6.9 & 6.9 \\
Fiber & 2.2 & 2.2 \\
Nitrogen free extracts (NFE) & 19.6 & 20 \\
Moisture & 10.0 & 10.0 \\
Energy (MJ/kg) & 17.5 & 17.5 \\
\hline
\end{tabular}

binomial model (Bliss and Fisher 1953) of distribution of S. chrysophrii in $\mathrm{C}$ and $\mathrm{T}$ fish population was compared by the maximum likelihood method (level of significance $=0.05$ ), and distribution asymmetry was estimated by variance to mean ratio (measure of over-dispersion), exponent $\mathrm{k}$ of the negative binomial (distribution asymmetry) and discrepancy index D (from 0 as uniform distribution, to 1 as maximum discrepancy) (Poulin, 1993).

Statistical analyses were performed after joining the results of three $\mathrm{C}$ and three $\mathrm{T}$ fish populations. An exact unconditional test, which keeps the prescribed type I error rate and has a higher statistical power in small sample size $(\mathrm{n}<100)$, was used to test difference in prevalence. Mood's median test was used to test the difference between the mean intensity of the two groups. Finally, the bootstrap two sample t-test was used to test the difference between mean abundance and intensity in two groups.

\section{RESULTS}

\section{Effect of CIM on growth parameters}

All estimated growth parameters including FW, FE, FCR and SGR showed insignificant differences between the two experimental groups (Table 2). Eleven fish died during the experiment, corresponding to 10 and $9 \%$ of the control and the group fed the modified diet, respectively. Anaemic gills were observed in a few dead fish. Few fish appeared lethargic and anorectic from both groups, but these symptoms diminished when water temperature dropped at the end of the experiment. No other experiment-irrelevant mortalities or abnormalities were evident during experimentation.

\section{Effect of CIM on parasitological parameters}

Gill examination of recipient fish showed no evidence of parasitic infection, including Sparicotyle chrysophrii,
Table 2. Growth parameters calculated as mean \pm SE in control and fed the modified diet gilthead sea bream Sparus aurata against infection with Sparicotyle chrysophrii.

\begin{tabular}{lcc}
\hline Growth parameters & Control & Fed modified diet \\
\hline Initial weight & $196.1 \pm 3.7$ & $199.7 \pm 4.1$ \\
Final weight & $295.3 \pm 5.4$ & $296.2 \pm 5.0$ \\
Feed efficiency & $51.2 \pm 2.8$ & $47.4 \pm 2.6$ \\
Feed conversion ratio & $2.0 \pm 0.1$ & $2.1 \pm 0.1$ \\
Specific growth rate & $0.74 \pm 0.03$ & $0.71 \pm 0.03$ \\
\hline
\end{tabular}

before their transfer to the experimental environment. The proportion of donor and healthy fish (0.5) and the coexistence period of two-week seemed to be adequate for the transmission of the disease in the challenge environment, since $100 \%$ prevalence was apparent in the examined recipient fish. The overall prevalence was $100 \%$ in both groups (Table 3).

The mean intensity of $S$. chrysophrii, measuring both adults and larvae in all gill arches, was 17.7 in control fish, while in fish fed the modified diet, it was significantly reduced $(P=0.0005)$ at 8.1 . CIM treatment resulted in reducing both adult and larval stages of the monogeneans (in respect to mean abundance and mean intensity). Interestingly, the prevalence of adults in control and treated fish did not differ, but it was significantly reduced in the larvae. In order to compare the preference of the monogeneans for particular positions within the gill chamber, we observed that the most parasitised was the fourth gill arch (the outermost) in both groups, and preferred both by adults and larvae (Table S1). In control fish, prevalence of adults and larvae differed between arches, as well as mean intensity of adults. In fish fed the modified diet, prevalence of both adult and larvae differed between arches, in contrast to the mean intensity (Table S2).

\section{DISCUSSION}

Sparicotyle chrysophrii remains undoubtedly the most crucial constraint for production of caged gilthead sea bream in the Mediterranean Sea. Chemical treatments, such as those based mainly on formalin, are usually effective but are blamed for environmental and consumer risks and are considered impractical and labour-intensive in cage environment. Therefore, alternative therapeutic strategies are of vital importance for ensuring sustainable and profitable farming of gilthead sea bream. Here, we describe a nonchemical approach where a dietary mixture of natural agents including $\mathrm{CA}$, organic iron and MOS was successfully applied as a nutritional improvement measure in $S$. chrysophrii-infected gilthead sea bream. Notably, the parasitic load significantly diminished in fish fed the modified diet after ten weeks of administration while growth remained unaffected. It is widely known that growth parameters are considerably affected in S. chrysophrii-infected gilthead sea bream and the FCR, specifically, is higher in infected individuals, both in controlled and field conditions (unpublished observations). In particular, FCR values measured during the present study (2-2.1) are higher compared to those found in growers of healthy gilthead sea bream (1.7) fed conventional diets in controlled environ- 
Table 3. Prevalence (\%) with Stern's exact 95\% confidence limits (CI), mean intensity (I), mean abundances with bootstrap 95\% CI (A) and variance-to-mean ratio of Sparicotyle chrysophrii isolated from control and CA-iron-MOS fed gilthead sea bream, Sparus aurata. Data on mean host length and weight are given with \pm SE. Exponent of the negative binomial $\left(\mathrm{k}^{*}\right)$ showed no statistical difference between observed and expected frequencies at $\mathrm{P}=0.05$. Discrepancy index value $(\mathrm{D}=0-1)$.

\begin{tabular}{|c|c|c|c|c|c|c|c|c|}
\hline Sparus aurata & $\begin{array}{l}\text { Mean length } \\
\pm \mathrm{SE}(\mathrm{cm})\end{array}$ & $\begin{array}{c}\text { Mean weight } \\
\pm \mathrm{SE}(\mathrm{g})\end{array}$ & Prevalence $(\%)$ & I & A CI & $\mathrm{v} / \mathrm{x}$ & $\mathrm{k}^{*}$ & $\mathrm{D}$ \\
\hline Control A + L $(\mathrm{N}=43)$ & $24.6 \pm 0.1$ & $295.3 \pm 5.4$ & $92-100(100)$ & $14.5-21.5(17.7)$ & $14.5-21.5(17.6)$ & 7.8 & 2.836 & 0.341 \\
\hline Control A & - & - & $92-100(100)$ & $7.4-11.7(9.3)$ & $7.4-11.7(9.3)$ & 5.7 & 2.148 & 0.402 \\
\hline Control A right gills & - & - & $75-96(88)$ & $3.9-6.0(4.9)$ & $3.3-5.4(4.3)$ & 29 & 1.909 & 0.440 \\
\hline Control A left gills & - & - & $88-100(98)$ & $4.0-6.5(5.1)$ & $3.9-6.3(5.0)$ & 3.5 & 2.232 & 0.424 \\
\hline Control L & - & - & $88-100(98)$ & $7.1-10.9(8.6)$ & $6.9-10.8(8.4)$ & 4.6 & 2.687 & 0.360 \\
\hline Control L right gills & - & - & $74-96(88)$ & $4.0-6.4(5.0)$ & $3.4-5.8(4.4)$ & 3.6 & 1.714 & 0.454 \\
\hline Control L left gills & - & - & $81-99(93)$ & $3.5-5.4(4.3)$ & $3.1-5.1(3.9)$ & 2.7 & 2.595 & 0.413 \\
\hline Treated $\mathrm{A}+\mathrm{L}(\mathrm{N}=44)$ & $25.1 \pm 0.1$ & $296.2 \pm 5.0$ & $85-100(96)$ & $6.9-9.6(8.1)$ & $6.5-9.2(7.8)$ & 2.8 & 3.721 & 0.324 \\
\hline Treated A & - & - & $85-100(96)$ & $3.7-5.5(4.4)$ & $3.5-5.2(4.2)$ & 2.1 & 4.582 & 0.358 \\
\hline Treated A right gills & - & - & $62-89(77)$ & $2.1-3.3(2.6)$ & $1.5-2.6(2.1)$ & 1.9 & 2.130 & 0.501 \\
\hline Treated A left gills & - & - & $70-93(84)$ & $2.1-3.2(2.6)$ & $1.7-2.8(2.2)$ & 1.5 & 4.021 & 0.441 \\
\hline Treated L & - & - & $65-90(80)$ & $3.7-5.4(4.4)$ & $2.7-4.4(3.5)$ & 2.6 & 1.656 & 0.457 \\
\hline Treated L right gills & - & - & $50-80(66)$ & $2.1-3.6(2.7)$ & $1.3-2.4(1.8)$ & 2.3 & 1.298 & 0.562 \\
\hline Treated L left gills & - & - & $52-81(68)$ & $1.9-3.4(2.6)$ & $1.3-2.4(1.8)$ & 2.2 & 1.479 & 0.552 \\
\hline
\end{tabular}

A - adults of S. chrysophrii; L - larvae of S. chrysophrii; v/x - variance to mean ration.

Table 4. Comparison of differences in prevalence, mean abundance and mean intensity of Sparicotyle chrysophrii between control (C) and caprylic acid-iron-MOS fed (T) gilthead sea bream, Sparus aurata.

\begin{tabular}{lcccccccc}
\hline & C vs T & CA vs TA & CL vs TL & CA vs CL & $\begin{array}{c}\text { CA left } v s \\
\text { CA right }\end{array}$ & $\begin{array}{c}\text { CL left } v s \\
\text { CL right }\end{array}$ & $\begin{array}{c}\text { TA vs TL } \\
\text { TA right }\end{array}$ & $\begin{array}{c}\text { TL left } v s \\
\text { TL right }\end{array}$ \\
\hline $\begin{array}{l}\text { Exact unconditional test } \\
\text { (prevalences) }\end{array}$ & 0.2836 & 0.2836 & $0.0097^{*}$ & 0.5820 & 0.202 & 0.681 & $0.0307^{*}$ & 0.5306 \\
$\begin{array}{l}\text { Bootstrap 2-sample t-test } \\
\text { (mean abundances) }\end{array}$ & $0.0000^{*}$ & $0.0000^{*}$ & $0.0005^{*}$ & 1.0000 & 0.442 & 0.556 & 0.2825 & 0.6690 \\
$\begin{array}{l}\text { Bootstrap 2-sample t-test } \\
\text { (mean intensities) }\end{array}$ & $0.0005^{*}$ & $0.0000^{*}$ & $0.0005^{*}$ & 0.6595 & 0.805 & 0.342 & 1.0000 \\
$\begin{array}{l}\text { Mood's median test } \\
\text { (mean intensities) }\end{array}$ & $0.0000^{*}$ & $0.0001^{*}$ & $0.0001^{*}$ & 0.827 & 0.368 & 0.495 & 0.822 & 0.9915 \\
\hline
\end{tabular}

A - adult of S. chrysophrii; L - larvae of S. chrysophrii; * statistically significant difference at $\mathrm{P}<0.05$.

ment (Fountoulaki et al. 2009), but much lower than those obtained in the field, due to better feeding management at the laboratory.

The CIM mixture proved to be effective for adult and larval stages, although it must ne noted that because of the application system (e.g. food), it cannot be assumed to have any effect on the eggs. Only recently have new data been obtained on the life cycle and treatment of S. chrysophrii (Sitjà-Bobadilla et al. 2006, Repullés-Albelda et al. 2012). Oncomiracidiam, the infectious free swimming ciliated larva, hatches from a fusiform and filamentous egg after 5-10 days at $20^{\circ} \mathrm{C}$, surviving up to 52 hours (at $20^{\circ} \mathrm{C}$ ) in sea water without an appropriate host (Repullés-Albelda et al. 2012). It has been proven in vitro that a $30 \mathrm{~min}$ bath in formalin (300 ppm) is 100\% effective for eggs, larvae and adults, and hydrogen peroxide (200 ppm) for larvae and adults (Sitjà-Bobadilla et al. 2006). Therefore, a combination of modified diet and chemical treatment of eggs could be a solution, especially because the diet alone does not decrease the probability of parasite presence at the farm (the prevalence is not significantly affected by the diet, in contrast to intensity).

Measured parameters of infection with S. chrysophrii in fish fed the modified diet show values approaching those observed in the wild (Reversat et al. 1992), with consistent systematic aggregation of the parasite in all measured cases (adults, larvae, number of gill arches). This suggests that the highest number of monogeneans is present in a small number of hosts and such aggregation would most likely induce mortalities in insignificant number of fish economically unburdening for the farmer.

For the first time, we evidenced the preference of this monogenean for the outermost gill arch, showing that all parasitic parameters (prevalence, abundance, intensity) declined till the innermost (first) gill arch. Such habitat restriction has been recognised for most monogeneans (Rohde 1977) and has been attributed to variations in water current on the gill surfaces or to the greater area of certain arches (Oliva and Luque 1998, Gutiérrez and Martorelli 1999, Crafford et al. 2014). However, there is no a consistent rule for all monogeneans, and there are cases where a homogeneous distribution pattern has been observed over all arches (Martins et al. 2014). It seems that the fourth gill arch sustains better conditions for $S$. chrysophrii even after application of the supplementary mixture, but its primary ecological importance for the parasite remains unclear.

In an earlier field trial, using CA alone at $200 \mathrm{mg} / \mathrm{kg}$ as a dietary additive for two months, results similar to those of the present study were obtained: intensity of $S$. chrysophrii was significantly reduced but no impact on growth was ob- 
served (Rigos et al. 2013). However, it should be noted that the intensity of the parasite was based on counting of adults on the two external gills of gilthead sea bream. Interestingly, the latter study suggests that the overall success against $S$. chrysophrii infections of gilthead sea bream is related to the progress of the disease at the time of treatment and thus its administration should be implemented during the first stages of the disease or even prior to the first signs of the disease. This observation was considered in the present study and, therefore, the modified diet was initiated prior to the challenge. However, the findings of the both studies failed to confirm that dietary supplementation with CA, apart from its proved antiparasitic potency, is able to compensate growth loss due to $S$. chrysophrii infection in gilthead sea bream, even thought iron and MOS were additionally included in the present study. This perhaps necessitates further optimisation of the added dietary compounds in future trials.

Other attempts to use natural compounds against S. chrysophrii have been limited to in vitro trials (Villar-Torres et al. 2014), but none of the examined substances (garlic bulbs, leaves of peppermint, valerian, sagebrush and passion flower) have produced a lethal effect on parasites at the tested dosages. Further in vivo investigation using higher concentrations of these compounds could perhaps lead to more convincing results about their potential antiparasitic efficacy. In previous studies, lower dosages of CA (25 mg/kg fish) were proved effective to control the diclidophorid monogenean Heterobothrium okamotoi Ogawa, 1991 affecting the tiger puffer, Takifugu rubripes Temminck et Schlegel (Hirazawa et al. 2000). No evaluation of fish growth was however included in the above study making any comparisons impossible.

Abiotic factors such as water temperature have been found to alter the efficacy of CA (Hirazawa et al. 2001). In particular, the anthelmintic effect of CA was more obvious at lower temperatures against $H$. okamotoi, possibly due to faster utilisation and the metabolic rate of the fish at higher water temperatures. The use of CA in colder season in Mediterranean is limiting, because $S$. chrysophrii infections proliferate in warm periods, suggesting that perhaps larger doses of CA should be administrated in warmer environments. However, preliminary laboratory attempts evaluating different dosing schedules for CA showed signs of depressed palatability of the modified diet when CA exceeded $1 \%$ in the diet. Perhaps, a feeding strategy of twomeals per day should be adopted, ensuring that the daily suggested dosing of the targeted compounds improved its tissue accumulation (Rigos et al. 2013) and thus further enhance the defence barrier against the parasite.

The infection model adopted in the present study appears to be successful for transferring $S$. chrysophrii from infected to naive (uninfected) gilthead sea bream. In particular, the coexistence period between donor and recipient fish using a $\mathrm{D} / \mathrm{R}$ ratio of 0.5 appeared sufficient. The range of mortalities during the experiment in both groups $(9-10 \%)$ is slightly lower then that reported recently by Rigos et al. (2015) for control fish in identical conditions (15\%), but similar to that documented from field infections with the parasite (Rigos et al. 2013). Although it has been demonstrated that the impact of $S$. chrysophrii is higher in smaller gilthead sea bream (Sitjà-Bobadilla and Alvarez-Pellitero 2009), prevalence reached $100 \%$ in the present study, in contrast to $93 \%$ at the end of the trial (10 weeks) using smaller individuals in the comparable study of Rigos et al. (2015).

In conclusion, the administration of the CIM mixture can significantly affect the evolution of $S$. chrysophrii infection in gilthead sea bream, being capable of reducing all stages of the monogenean. However, this alternative approach requires additional improvement since no direct effects on growth were apparent, potentially leaving space for further optimisation of the added dietary compounds.

Acknowledgements. This project has received funding from the European Union's Horizon 2020 research and innovation programme under grant agreement No. 634429. This publication reflects the views of the authors only, and the European Commission cannot be held responsible for any use which may be made of the information contained therein.

\section{REFERENCES}

Agius C., Agbede S.A. 1984: An electron microscopical study on the genesis of lipofuscin, melanin and haemosiderin in the haemopoietic tissues of fish. J. Fish Biol. 24: 471-488.

Agius C., Roberts R.J. 1981: Effects of starvation on the melano-macrophage centres of fish. J. Fish Biol. 19: 161-169.

Alvarez-Pellitero P. 2004: Report about fish parasitic diseases. In: P. Alvarez-Pellitero, J.L. Barja, B. Basurco, F. Berthe and A.E. Toranzo (Eds.), Mediterranean Aquaculture Diagnostic Laboratories Zaragoza, CIHEAM, Options Méditerranéennes, no. 49, Série B., pp. 103-130.

Antonello J., Massault C., Franch R., Haley C., PellizZari C., Bovo G., Patarnello T., De Koning D.-J., BargELLONI L. 2009: Estimates of heritability and genetic correlation for body length and resistance to fish pasteurellosis in the gilthead sea bream (Sparus aurata L.). Aquaculture 298: 29-35.

Antonelli L., Quilichini Y., Marchand B. 2010: Sparicotyle chrysophrii (Van Beneden and Hesse 1863) (Monogenea: Polyopisthocotylea) parasite of cultured Gilthead sea bream Sparus aurata (Linnaeus 1758) (Pisces: Teleostei) from Corsica: ecological and morphological study. Parasitol. Res. 107: 389-398.

Bergsson G., Arnfinnsson J., Karlsson S.M., SteingrímsSON O., ThORMAR H. 1998: In vitro inactivation of Chlamydia trachomatis by fatty acids and monoglycerides. Antimicrob. Agents Chemother. 42: 2290-2294.

Bliss C.I., Fisher R.A. 1953: Fitting the negative binomial distribution to biological data. Biometrics 9: 176-200.20014

Bush A.O., Lafferty K.D., Lotz J.M., Shostak A.W. 1997: Parasitology meets ecology on its own terms: Margolis et al. revisited. J. Parasitol. 83: 575-583.

Crafford D., Luus-Powell W., Avenant-Oldewage A. 2014: Monogenean parasites from fishes of the Vaal Dam, Gauteng Province, South Africa II. New locality records. Acta Parasitol. 59: 485-492.

Cruz E., Silva M.P., Freitas M.S., Orge M.L. 1997: Co-infection by monogenetic trematodes of the genus Microcotyle, Beneden \& Hesse, 1863, Lamellodiscus ignoratus Palombi, 1943, the protozoan Trichodina sp. Ehrenberg, 1838 and the 
presence of epitheliocystis, Vibrio alginolyticus and V. vulnificus in cultured seabream (Sparus aurata L.) in Portugal. Bull. Eur. Ass. Fish Pathol. 17: 40-42.

De Vico G., Cataldi M., Carella F., Marino F., Passantino A. 2008: Histological, histochemical and morphometric changes of splenic melanomacrophage centers (Smmcs) in Sparicotyle-infected cultured sea breams (Sparus aurata). Immunopharmacol. Immunotoxicol. 30: 27-35.

Euzet L., Combes C. 1998: The selection of habitats among the monogenea. Int. J. Parasitol. 28: 1645-1652.

Faisal M., Iman E.A. 1990: Microcotyle chrysophrii (Monogenea: Polyopisthocotylea), a pathogen of cultured and wild gilthead sea bream, Sparus aurata. In: F.O. Perkins and T.C. Cheng (Eds.), Pathology in Marine Science. Academic Press, San Diego CA, pp. 283-290.

Fountoulaki E., Vasilaki A., Hurtado R., Grigorakis K., Karacostas I., Nengas I., Rigos G., Kotzamanis Y., VeNOU B., Alexis M.N. 2009: Fish oil substitution by vegetable oils in commercial diets for gilthead sea bream (Sparus aurata L.); effects on growth performance, flesh quality, fillet fatty acid profile. Recovery of fatty acid profiles by a fish oil finishing diet under fluctuating water temperatures. Aquaculture 289: 317-326.

Gutiérrez P., Martorelli S. 1999: Hemibranch preference by freshwater monogeneans a function of gill area, water current, or both? Folia Parasitol. 46: 263-266.

Henry M.A., Nikoloudaki C., Tsigenopoulos C., Rigos G. 2015: Strong effect of long-term Sparicotyle chrysophrii infection on the cellular and innate immune responses of gilthead sea bream, Sparus aurata. Dev. Comp. Immunol. 51: 185-193.

Hirazawa N., Ohtaka T., Hata K. 2000: Challenge trials on the anthelmintic effect of drugs and natural agents against the monogenean Heterobothrium okamotoi in the tiger puffer Takifugu rubripes. Aquaculture 188: 1-13.

Hirazawa N., Oshima S., Mitsuboshi T., Hata K. 2001: The anthelmintic effect of medium-chain fatty acids against the monogenean Heterobothrium okamotoi in the tiger puffer Takifugu rubripes: evaluation of doses of caprylic acid at different water temperatures. Aquaculture 195: 211-223.

Kato N., Shibasaki I. 1976: Combined effect of citric and polyphosphoric acids on the antibacterial activity of monoglycerides. J. Antibact. Antif. Agents 4: 254-261.

Mahmoud N.E., Mahmoud A.M., Fahmy M.M. 2014: Parasitological and comparative pathological studies on monogenean infestation of cultured sea bream (Sparus aurata, Spariidae) in Egypt. Oceanography 2: 129.

Martins M.L., SÁ A.R.S., Jerônimo G.T., TAncredo K.R., Gonçalves E.L.T., Bampi D., Speck G.M., Sandin A.M. 2014: Microhabitat preference and seasonality of gill monogeneans in Nile tilapia reared in southern Brazil. Neotrop. Helminthol. 8: 47-58.

Nowak B.F. 2007: Parasitic diseases in marine cage culture - an example of experimental evolution of parasites? Int. J Parasitol. 37: 581-588.

Oliva M.E., LuQue J.L. 1998: Distribution patterns of Microcotyle nemadactylus (Monogenea) on gill filaments of Cheilodactylus variegatus (Teleostei). Mem. Instit. Oswaldo Cruz 93: 477-478.

Poulin R. 1993: The disparity between observed and uniform distributions: a new look at parasite aggregation. Int. J. Parasitol. 23: 937-944.

Radujković B.M., Šundić D. 2014: Parasitic flatworms (Platyhelminthes: Monogenea, Digenea, Cestoda) of fishes from the Adriatic Sea. Nat. Monten. Podg. 13: 7-280.
Reiczigel J., RózSA L. 2005: Quantitative parasitology 3.0 Secondary Quantitative parasitology 3.0. http:/www.zoologia.hu/ qp/qp.html.

Repullés-Albelda A., Holzer A.S., Raga J.A., Montero F.E. 2012: Oncomiracidial development, survival and swimming behaviour of the monogenean Sparicotyle chrysophrii (Van Beneden and Hesse, 1863). Aquaculture 338-341: 47-55.

Reversat J., Silan P., Maillard C. 1992: Structure of monogenean populations, ectoparasites of the gilthead sea bream Sparus aurata. Mar. Biol. 112: 43-47.

Rigos G., Fountoulaki E., Cotou E., Dotsika E., Dourala N., Karacostas I. 2013: Tissue distribution and field evaluation of caprylic acid against natural infections of Sparicotyle chrysophrii in cage-reared gilthead sea bream Sparus aurata. Aquaculture 408-409: 15-19.

Rigos G., Henry M., Tsigenopoulos C. 2015: Sparicotyle chrysophrii and gilthead sea bream - potential experimental infection model. Bull. Eur. Ass. Fish Pathol. 35: 49-53.

Rigos G., Samartzis A., Henry M., Fountoulaki E., Cotou E., Sweetman J., Davies S., Nengas I. 2010: Effects of additive iron on growth, tissue distribution, haematology and immunology of gilthead sea bream, Sparus aurata. Aquac. Int. 18: 1093-1104.

RoHDe K. 1977: A non-competitive mechanism responsible for restricting niches. Zool. Anz. 199: 164-172.

Rózsa L., Reiczigel J., Majoros G. 2000: Quantifying parasites in samples of hosts. J. Parasitol. 86: 228-232.

SANZ F. 1992: Mortality of cultured seabream (Sparus aurata) caused by an infection with a trematode of the genus Microcotyle. Bull. Eur. Ass. Fish Pathol. 12: 186-188.

Sitjà-Bobadilla A., Alvarez-Pellitero P. 2009: Experimental transmission of Sparicotyle chrysophrii (Monogenea: Polyopisthocotylea) to gilthead seabream (Sparus aurata) and histopathology of the infection. Folia Parasitol. 56: 143-151.

Sitjà-Bobadilla A., de Felipe M.C., Alvarez-Pellitero P. 2006: In vivo and in vitro treatments against Sparicotyle chrysophrii (Monogenea: Microcotylidae) parasitizing the gills of gilthead sea bream (Sparus aurata L.). Aquaculture 261: 856-864.

Sun C.Q., O’Connor C.J., Roberton A.M. 2003: Antibacterial actions of fatty acids and monoglycerides against Helicobacter pylori. FEMS Immunol. Med. Microbiol. 36: 9-17.

Sweetman J.W., Torrecillas S., Dimitroglou A., Rider S., Davies S.J., IzQuierdo M.S. 2010: Enhancing the natural defences and barrier protection of aquaculture species. Aquacult. Res. 41: 345-355.

Torrecillas S., Makol A., Caballero M.J., Montero D., Robaina L., Real F., Sweetman J., Tort L., Izquierdo M.S. 2007: Immune stimulation and improved infection resistance in European sea bass (Dicentrarchus labrax) fed mannan oligosaccharides. Fish Shellfish Immunol. 23: 969-981.

Vagianou S., Athanassopoulou F., Ragias V., Di Cave D., Leontides L., Golomazou E. 2006: Prevalence and pathology of ectoparasites of Mediterranean sea bream and sea bass reared under different environmental and aquaculture conditions. Israeli J. Aquacult. Bamidgeh 58: 78-88.

Villar-Torres M., Raga J.A., Ahuir-Baraja A.E., MonteRO F.E. 2014: Preliminary study on the effect of in vitro vegetal treatments against the monogenean Sparicotyle chrysophrii parasite of Sparus aurata. Aquaculture Europe Society, E.A. Donostia, San Sebastián, 14-17 October 2014.

Cite this article as: Rigos G., Mladineo I., Nikoloudaki C., Vrbatovic A., Kogiannou D. 2016: Application of compound mixture of caprylic acid, iron and mannan oligosaccharide against Sparicotyle chrysophrii (Monogenea: Polyopisthocotylea) in gilthead sea bream, Sparus aurata. Folia Parasitol. 63: 027. 